\title{
Unidades do Relevo de Mato Grosso: Uma Proposta de Classificação
}

\author{
Hugo José Scheuer Werle \\ Mauricio Alves da Silva \\ Universidade Federal de Mato Grosso - UFMT \\ Departamento de Geografia \\ Av. Fernando Corrêa da Costa, $\mathrm{S} / \mathrm{N}$ \\ CEP: 78.060-900 - Cuiabá-MT \\ hugoswik@nutecnet.com.br
}

\begin{abstract}
This paper stablishes a classification of the relief of the state of Mato Grosso never seen the fore. It utilizes the works of Radambrasil and PCBAP, as well as our professional experience in geomorphology researches. Being however pased on the methodology of Geomorphological Mapping establishet by Jurandir L. S. Ross (1985).
\end{abstract}

Keywords: Geomorphology, Mato Grosso, relief classification.

\section{Introdução}

Os conteúdos sobre o relevo mato-grossense, reproduzidos nas escolas de primeiro e segundo graus para os alunos na disciplina de geografia e correlatas, bem como aos alunos dos cursos de nivel superior, são em sua grande maioria adaptações de conhecimentos, por vezes muito antigos e não atualizados, destituídos de abordagem cartográfica, ou, quando existente, apresentada numa escala inadequada para um bom entendimento. Outras vezes constituem-se de publicações geradas em centros distantes, principalmente São Paulo e Rio de Janeiro, e cujo objetivo, é dotar os alunos daqueles centros de conhecimentos com enfoque maior na sua própria realidade.

O exemplo mais ilustrativo disto, é a utilização, dos conhecimentos e conceitos produzidos a meio século pelo geógrafo e professor, Aroldo de Azevedo, ou ainda das classificações definidas pelo também geógrafo e pesquisador, professor Aziz Ab'Saber durante a década de 1960 . Todavia, nos últimos anos, foram gerados novos conhecimentos geomorfológicos que devem necessariamente ser sistematizados e incorporados nos conteúdos das aulas de geografia física do estado de Mato Grosso.

Desta forma, a preocupação fundamental deste trabalho é aproveitar as novas produções e conhecimentos gerados, aliada a nossa experiência profissional como professor universitário e pesquisador, para apresentar uma classificação das unidades de relevo, definidas basicamente nas grandes formas, as unidades morfoesculturais.

\section{Metodologia}

Esta classificação é baseada principalmente nos resultados das pesquisas desenvolvidas pelo Projeto Radambrasil, mais especificamente nos volumes que se referem ao território de Mato Grosso, nos diversos trabalhos sobre classificação e taxonomia do relevo publicados pelo Professor Dr. Jurandir L. S. Ross, desde 1985, cujos bases estão ancoradas em Mecerjakov (1968), e aperfeiçoada posteriormente por Ross (1991, 1992) e Ross \& Moroz (1996). Contribuiu também, nossa experiência enquanto pesquisadores da área de geografia fisica, mais especificamente de geomorfologia, dentre os quais destacamos o trabalho de mapeamento geomorfológico do Plano de Conservação da Bacia do Alto Paraguai - PCBAP, desenvolvido em 1995/1996 (inédito).

Tendo como pressuposto básico o conceito de morfoescultura, que concebe a presença de uma ou mais estruturas geológicas que embasam cada unidade de relevo definida, tem-se o modelado e a macro compartimentação das superficies como elemento principal para estabelecer a classificação. Com base nestes critérios foram definidas 37 unidades de relevo, cujas características básicas serão descritas de forma sucinta a seguir:

\section{UNIDADES DE RELEVO DEFINIDAS PARA O ESTADO DE Mato Grosso}

Domínio Morfoestrutural do Cinturāo Orogênico Paraguai-Araguaia

Morfoestrutura dos Dobramentos Cuiabá

1 - Depressão Cuiabana - Superficie em rampa, onde na extremidade sul quando coalece com o pantanal apresenta 150 metros de altitude e nos setores norte e oeste, limite com as serras Residuais do Alto Paraguai, bem como a leste, limite com as escarpas da Chapada 
dos Guimarães, Planalto do Arruda-Mutum e o Planalto do Casca tem 400 metros de altitude. Apresenta um modelado levemente convexo esculpido nos metassedimentos do grupo Cuiabá

2 - Depressão de São Jerônimo-Mimoso - Estreita faixa deprimida, situada entre os pantanais mato-grossenses e a serra de São Jerônimo, limite sudoeste da Chapada dos Guimarães e Oeste do Chapadão do rio Correntes. Apresenta relevos convexos com estreitos interflúvios esculpidos em rochas do grupo Cuiabá

3 - Planalto do Arruda-Mutum - Unidade de relevo com interflúvios pequenos e vertentes convexas no topo esculpidas nas rochas do Grupo Cuiabá. Apresenta altitudes em torno de $\mathbf{4 0 0}$ metros nas áreas baixas mais planas a sul, oeste e norte, contato com a Depressão Cuiabana, e 500 metros nas escarpas que a limitam com o Planalto do Casca e a Chapada dos Guimarães a Leste.

\section{Morfoestrutura dos Dobramentos do Alto Paraguai} 4 - Serras residuais do Alto Paraguai (Província Serrana) - Faixa de dobramentos em anticlinais escavados e sinclinais soerguidos constituídos de sedimentos do pré-cambriano. Os mesmos foram intensamente desgastados por ciclos erosivos, apresentando ainda assim, altitudes entre 600 e 850 metros. As formas são aguçadas e aparecem profundos vales em " $V$ " onde a drenagem encaixada é conduzida pelas linhas de falhas e fraturas. A unidade pode ser dividida em três setores: no sul destacam-se as serras das Araras, Vãozinho e Camarinha; no setor central, onde nasce 0 rio Paraguai, destacam-se as serras do Tira Sentido, Vira Saia, Tombador, Cancela, Caixa Furada, Santa Rita e do Cuiabá, e finalmente, no Setor de direção leste-oeste, aparecem as serras do Morro Selado e a Serra Azul.

5 - Depressão do Alto Paraguai - Área deprimida com altitudes entre 120 e 300 metros, limita-se a leste com as serras Residuais do Alto Paraguai, ao norte com o planalto do Tapirapuã, a oeste com o planalto do rio Branco e ao sul coalece os pantanais. $O$ relevo constitui-se de interflúvios amplos esculpidos em rochas pré-cambrianas e sedimentos que datam do terciário e quaternário, formando planicies e terraços fluviais. Os rios mais importantes da área são o baixo curso do rio Sepotuba e o alto curso do rio Paraguai. 6- Depressão Interplanáltica de Paranatinga - Extensa superficie deprimida limitada ao norte e leste pelo Planalto dos Parecis, ao sul pelo Planalto do Guimarães e também ao sul e oeste pelas Serras residuais do Alto Paraguai. As altitudes variam de 400 a 500 metros, apresentando relevo com interflúvios médios e vertentes convexas. A drenagem constitui-se do rio Teles Pires e seus formadores, Paranatinga e São Manuel no setor oeste e Culuene e Curisevo no setor leste.
Domínio Morfoestrutural da Plataforma Amazônica 7 - Serra dos Apiacás - Esta unidade de formato estreito e alongado no sentido leste-oeste obedece alinhamentos estruturais de rochas pré-cambrianas. As altitudes atingem 450 metros e o relevo apresenta formas aguçadas e vales profundos, nos quais instalamse afluentes do rio Teles Pires que a seciona transversalmente.

8 - Setor Meridional das Serras e Chapada do Cachimbo - Situa-se na divisa com o estado do Pará emergindo da Depressão Sul Amazônica como um agregado de formas residuais dissecadas, com topo, planos, modelados em sedimentos pré-cambrianos. Suas altitudes variam de 400 a 600 metros, e apresenta os rios Braço Sul, Braço Norte, porção superior do Peixoto de Azevedo e setor da jusante do rio Cristalino como os principais da área.

9 - Serra dos Caiabis - Situa-se no norte de Mato Grosso, emergindo com um formato de elipse da Depressão Sul Amazônica. Compreende um "graben" topograficamente invertido, sendo constituído de rochas do Proterozóico Superior. Apresenta relevos tabulares com diversos patamares estruturais com altitudes de 400 a 450 metros. Seus limites são bordas escarpadas nas quais nascem os formadores dos dois rios principais da área, o Matrinchã e o Apiacá.

10 - Chapada de Dardanelos - Situa-se no noroeste do estado, destacando-se do entorno como um bloco de relevo residual bastante plano. É constituída basicamente de rochas sedimentares da formação Dardanelos (Proterozóico médio) e delimitada por escarpas de linhas de falha. O relevo apresenta altitudes que variam de 230 a 450 metros e a drenagem é constituída pelo rio Aripuanã e seus afluentes da montante

11 - Planaltos residuais do Norte de Mato Grosso (Sul Amazônicos) - Foram definidas como unidade os inúmeros blocos de relevo de dimensões menores, constituídos por elevações ou serras pouco conhecidas ou mesmo sem denominação especifica dispersos pelo norte de Mato Grosso. De Leste para oeste, à direita do rio Xingu, destacamos a serra do Matão, à esquerda do mesmo rio as serras de São Pedro e dos Jurunas. Estas serras, cujas altitudes ultrapassam 400 metros, apresentam-se como cristas alongadas condicionadas pelas estrutura litológica do pré-cambriano superior. Os terrenos planos são de pouca expressão areal e sendo a primeira drenada por afluentes dos rio Araguaia e as outras pelos do Xingu.

Entre os rios Teles Pires e Juruena, ao sul da serra de Apiacás, encontra-se a porção contínua mais extensa desta unidade, que porém não apresenta denominação específica. Esta área, cujo embasamento apresenta rochas do grupo Uatumã (pré-cambriano superior), 
apresenta relevo bastante ondulado com topos convexos e altitudes de até 450 metros. Sua drenagem é constituída de pequenos rios, como o Apiacá, que correm para o Teles Pires.

Mais para oeste, margem esquerda do rio Juruena, aparecem várias porções isoladas da unidade, dentre as quais destacamos: serra do Pacutinga, do Pajurá, da Fortaleza, das Panelas, e da Providência. Geralmente a litologia constitui-se de rochas do complexo Xingu ou da formação Dardanelos. O relevo nestas áreas, drenadas por afluentes do rio Ji-paraná, constitui-se de cristas com vertentes muito pronunciadas e cujas altitudes variam de 200 a 400 metros.

12 - Depressão Sul Amazônica - Abrange toda faixa a norte do Planalto dos Parecis, em quase toda extensão com os estados do Pará e Amazonas. É a superficie base da qual se destacam todos os planaltos residuais do norte de Mato Grosso. Litologicamente a área é bem variada apresentando rochas do complexo Xingu, vulcânicas e graníticas do supergrupo Uatumã, basálticas do Caiabis e sedimentos do grupo beneficente, dentre outras. As altitudes são modestas ficando entre 200 e 300 metros e a característica mais marcante da unidade é a intensa dissecação homogênea que sofreram as diferentes rochas que a compõem. A drenagem mostra-se adaptada à rede de falhas $e$ fraturas, apresentando algumas faixas de deposição aluvial ao longo dos rios Juruena, Teles Pires, CururuAçu, ou ainda, trechos encachoeirados como dos rios Teles Pires, Arinos e Juruena, em virtude de romperem linhas estruturais do embasamento.

13 - Depressão do Guaporé - Constitui-se numa faixa de relevo a oeste do Planalto do Jaurú e da Chapada dos Parecis e que envolve as unidades serranas da bacia do Guaporé, com a qual limita-se por escarpas abruptas. $O$ relevo apresenta altitudes que variam de 200 a 300 metros, sendo que nos setores mais baixos, que envolvem a planície e os pantanais do Guaporé temos a presença de áreas pediplanadas e inumadas por sedimentos quaternários, e, formas tabulares com amplos interflúvios nas superficies de maior altitude.

14 - Serra de Ricardo Franco - Unidade de pequena expressão areal, situada na fronteira com a Bolívia limita-se com as Planícies e Pantanais do Guaporé e com a Depressão do Guaporé. Relevo residual com litologia do grupo Aguapeí, apresenta altitudes que variam de 350 metros até os expressivos 1070 metros, possivelmente a maior do estado. As feições apresentam setores aplanados, tendo porém como característica mais importante ser ondulado e com presença de cristas nas áreas escarpadas. $O$ rio verde, que nasce no setor sul, inflete para norte, servindo como marco divisor de fronteira, é o mais importante da área.

15 - Serra de São Vicente - Pequena unidade situada a noroeste de Vila Bela da Santíssima Trindade.
Apresenta-se como bloco compacto com extensão de 55 $\mathrm{Km}$ e $15 \mathrm{Km}$ de largura. Constituída de rochas précambrianas do grupo Aguapeí, possui relevo com formas aguçadas e convexas $e$ as altitudes variam de 650 a 800 metros. A drenagem constitui-se em sua maioria de rios intermitentes bastante encaixados nas falhas geológicas.

16 - Conjunto de Cristas das serras da Borda do Cágado, Salto do Aguapeí e do Caldeirão - Unidade próximo à cidade de Pontes e Lacerda. De formato alongado e estreito, constituí-se de anticlinais e sinclinais dispostos no sentido sudeste-noroeste. As rochas pré-cambrianas do grupo Aguapeí são a base geológica de um relevo em cristas aguçadas e assimétricas com altitudes máximas de 750 metros. A drenagem é feita pelo rio Guaporé e Aguapei que secionam as serras.

17 - Serra de Santa Bárbara - Situada no sudoeste do estado, apresenta altitudes que variam de 500 a 900 metros. A presença de anticlinais escavados e sinclinais erodidos ocasionaram o aparecimento de um relevo com escarpas cuestiformes e cristas alongadas. A drenagem instalada e concuzida pelas linhas de fraqueza, apresenta como rio que corre para norte o Alegre, formador do Guaporé, para leste o rio Aguapei, contribuinte do Paraguai, e, para o sul, o córrego Tarumã.

18 - Planalto do Jaurú - Situada a sul da Chapada dos Parecis, leste da depressão do Alto Guaporé e das serras do Cágado e Aguapeí e oeste da depressão do Alto Paraguai. Sua base geológica são rochas do précambrianas do Complexo Xingu. A altitude varia de 300 metros a sul e 600 metros no norte, no contato com a Chapada dos Parecis, apresentando no conjunto, formas convexas no topo, e, interflúvios amplos no sul e menores no norte. A drenagem para leste é feita pelos rios Jaurú e Aguapeí e para oeste pelo rio Guaporé e afluentes.

19 - Depressão do Rio Jaurú - Unidade cujos limites oeste são o Planalto do Jaurú, no norte o Planalto do Rio Branco e leste a Depressão do Alto Paraguai, tendo aqui como referência a serra do Padre Inácio. Com altitudes que variam de 150 a 300 metros, apresenta relevo com topografia suave, caracterizado por interflúvios bastante amplos e planícies aluviais bem desenvolvidas ao longo dos rios Jaurú, das Pitas e Aguapeí, no centro norte e no Corrixo Grande e Córrego Acorizal na porção sul da unidade.

20 - Planalto do Rio Branco - Unidade situada ao sul da Chapada dos Parecis, oeste do Planalto de Tapirapuã e norte e leste da depressão do Alto Paraguai. Constituída principalmente por rochas do Grupo Aguapeí nas quais apresenta relevo montanhoso com cristas em alguns setores e outras com relevos tabulares conservados, cujas altitudes variam de 400 a 600 metros, e são 
claramente delimitadas por escarpas estruturais. A área é drenada pelos rio Branco e rio Cabaçal.

21 - Planícies e Pantanais do Médio e Alto Guaporé Unidade situada no extremo sudoeste do estado, desenvolvendo-se ao longo do rio Guaporé e seus afluentes limitada pela Depressão do Guaporé. A geologia constitui-se de sedimentos quaternários da formação Guaporé. As altitudes variam de 180 a 220 metros, tendo áreas periodicamente e outras permanente inundáveis, em virtude das águas fluviopluviais.

\section{Domínio Morfoestrutural da Bacia Sedimentar do Paraná. Planalto dos Guimarães}

22 - Chapada dos Guimarães - Relevo suavemente ondulado com altitudes entre 650 e 850 metros. Os setores mais elevados constituem-se nas superficies mais elevadas da estrutura no estado de Mato Grosso e são sustentados pelo arenito Botucatu Encontra-se delimitada por bordas erosivas e patamares estruturais com os Planaltos do Casca, Alcantilados e ArrudaMutum, bem como com a depressão Cuiabana. Apresenta, via de regra, o relevo aplanado com drenagem de pequenos córregos, pouco entalhados e amplos espaços interfluviais.

23 - Planalto do Casca - Unidade de relevo mais rebaixada, embutida no setor noroeste da Chapada dos Guimarães, com as quais se delimita por meio de escarpas erosivas. Apresenta altitudes que variam de 400 até 600 metros, possuindo feições tabulares e convexas com presença de relevos residuais esculpidas em arenitos da formação Bauru e Botucatu. A drenagem constitui-se do rio da Casca e seus afluentes, tais como o Roncador e Quilombo. Assim como estes, a maioria dos rios menores nascem na Chapada dos Guimarães e descem para unidade escavando profundos "canyons".

24 - Planalto do rio das Mortes - Unidade mais setentrional da morfoestrutura, sustentada pela formação Bauru, a qual apresenta espessa cobertura detrito-lateritica. $O$ rio das Mortes e seus afluentes são o principal eixo de drenagem de um relevo plano com amplas áreas interfluviais. No setor norte e Leste da Unidade aparecem áreas mais rebaixadas drenadas pelas cabeceiras e formadores dos rios Teles Pires e Coluene.

25 - Planalto dos Alcantilados - Unidade embutida na borda sul do Planalto do Rio das Mortes, tem como característica mais importante a presença de vertentes abruptas com escarpas alcantiladas, originadas de intensa tectonia que afetou as rochas das Formações Ponta Grossa, Aquidauana, Palermo e Botucatu. Os terrenos mais conspícuos são os residuais em forma de "mesa" que surgem em função da erosão diferencial e da tectônica do passado. As altitudes variam de 400 a 600 metros. A rede de drenagem instalada nas falhas da estrutura constitui-se do rio das Garças e seus formadores, afluentes da cabeceira do Araguaia e os formadores dos rios Poxoréo, Vermelho e São Lourenço.

26 - Depressão de Rondonópolis - É a mais rebaixada das unidades do Planalto dos Guimarães, apresentando altitudes máximas de 300 metros. É produto do trabalho de escavação do médio e baixo curso dos rios São Lourenço, Vermelho e seus afluentes, nos arenitos Aquidauana e Ponta Grossa. As formas são tabulares e convexas, com interflúvios bastante amplos e incisão dos canais de drenagem bastante profunda nos setores mais altos e pequenas nas partes inferiores.

27 - Planalto do Taquari-Itiquira - Unidade situada no extremo sudeste do estado, apresenta-se como área com amplos setores planos e outros com leve declividade leste-oeste, limite de Mato Grosso com Goiás e Mato Grosso do Sul, sendo delimitada em quase todo seu perímetro por escarpas erosivas e estruturais. A norte seus limites são o Planalto dos Alcantilados e ao sul e sudoeste o Chapadão das Emas. As altitudes variam de 500 metros no médio curso do rio Itiquira a 850 metros nas nascentes do rio Taquari.

28 - Chapada do Rio Correntes - Situada no sul, adentrando-se no Mato Grosso do Sul, tendo a depressão de São Jerônimo-Mimoso a oeste, depressão de Rondonópolis a norte e o planalto do TaquariItiquira a leste. A altitude média varia em torno de 500 metros e apresenta relevo ondulado com grandes espaços interfluviais, tendo como rios mais importantes o Itiquira e Correntes.

Domínio Morfostrutural da Bacia Sedimentar do Parecis

29 - Planaltos dos Parecis - Constitui-se de imensa área contínua no centro do estado, que ao sul apresenta altitudes em torno de 600 metros, no limite com a Depressão Interplanáltica de Paranatinga e Serras Resicuais do Alto Paraguai e 300 metros ao norte, quando coalece com a Depressão Sul Amazônica. O embasamento constitui-se de arenitos do grupo Parecis (Mesozóico): formações Utiariti e Salto das Nuvens, com recobrimento Detrito-laterítico em amplas áreas. $\mathrm{O}$ relevo apresenta-se com superficies bastante planas, amplos interflúvios e drenagem com pequeno aprofundamento. Os principais rios da unidade nascem fora dela, cortando-a geralmente no sentido norte-sul, dentre os quais destacamos: Xingu, Teles Pires, Arinos, do Sangue e Juruena.

30 - Chapada dos Parecis - Aparece no Oeste do estado, circundada ao norte e leste pelo Planalto dos Parecis, ao sul pelos Planaltos de Tapirapuã, Rio Branco e Jaurí e a Sudoeste e oeste pelas depressões do Jaurú e do 
Guaporé. É uma superficie de cimeira, variando de 700 a 400 metros e cujo embasamento constitui-se arenitos do grupo Parecis (Mesozóico), especificamente a formação Utiariti com recobrimento Detrito-lateritico em amplas áreas. O relevo é suavemente ondulado a plano, apresentando amplos interflúvios. A drenagem constitui-se das nascentes dos rios do Sangue, Papagaio, Juruena, Sepotuba, Jaurú e Guaporé.

31 - Planal to de Tapirapuã - Pequena unidade no centro do estado cujos limites leste, norte e oeste são a Chapada dos Parecis, tendo a oeste também o Planalto do Rio Branco, e, ao Sul a depressão do Alto Paraguai. O embasamento geológico constitui-se dos basaltos da formação Tapirapuã e de arenitos da formação Salto das Nuvens, ambas do Cretáceo. Esta unidade cujas altitudes variam de 400 a 600 metros, apresenta-se como um degrau entre a Chapada dos Parecis e a Depressão do Alto Paraguai. Possui um relevo suavemente ondulado, com um embaciamento geral para o centro da área onde escoa o rio Sepotuba.

\section{Dominio Morfoestrutural das Planícies e Pantanais Mato-grossenses}

32 - Pantanal do Corixo Grande-Jauru-Paraguai Também conhecido como Pantanal do Descalvado ocorre no noroeste da zona pantaneira. É drenado pelos córregos Saloba, Gambá Manhoso, Padre Inácio e o riacho São Sebastião. Com altitudes entre 100 e 150 metros, a área possui inúmeras planícies deprimidas drenadas por "corixos" e "vazantes", e em determinados trechos, "baias" isoladas. A litologia consiste de depósitos aluvionais da formação pantanal. É nesta área que o rio Paraguai adentra ao pantanal propriamente dito.

33 - Pantanal do Cuiabá-Bento Gomes-Paraguaizinho Mais conhecido como Pantanal de Poconé. Seu limite norte é a Depressão Cuiabana, a leste e sul o Pantanal de Paiaguás e a oeste a Província Serrana. A litologia constitui-se de depósitos da formação Pantanal. Apresenta uma grande faixa de fraca inundação a norte com uma altimetria superior aos 130 metros. Próximo ao rio Cuiabá e junto à Província Serrana, tem áreas medianamente inundáveis. Em direção ao sul, as altimetrias passam para 100 e 110 metros. As áreas menos úmidas do norte, possuem pequenos cursos de drenagem dendríticos; mais ao sul, os "corixos" mostram um padrão paralelo; e a jusante, um padrão anastomosado.

34 - Pantanal de Paiaguás - É o mais meridional dos "Pantanais" mato-grossenses, apresentando os depósitos aluviais dos rios Paraguai e Cuiabá. Toda essa planicie é constituída por lagoas de várias dimensões. As maiores estão na fronteira com a Bolívia: Uberaba, Guaiba e Mandioré. Próximo às "baías" de Chacororé e
Chamariana, a planicie caracteriza-se como lacustre, e próximo ao rio Cuiabá é fluviolacustre. A sul daquelas "baías", na ilha de Piraim, a planície apresenta uma série de "baías" e meandros abandonados. Esta área possui aluviões atuais que cobrem sedimentos mais antigos.

35 - Pantanal do Itiquira-São Lourenco-Cuiabá - Área de mediano alagamento, porém próximo à confluência do Itiquira com o Piquiri, tem-se uma área de forte inundação. A litologia constitui-se de depósitos aluvionais da Formação Pantanal. O rio São Lourenço adentra o pantanal em torno de $110 \mathrm{~m}$. O entulhamento no interflúvio Boca Brava-braço do São LourençoItiquira, forma uma ilha denominada localmente de Bananal. O rio Itiquira apresenta um curso meândrico e comanda toda drenagem circunvizinha, até chegar ao rio Cuiabá. Todos estes cursos possuem largas faixas de planicies aluviais.

Domínio Morfoestrutural da Depressão e Planície do Araquaia

36 - Depressão do Araguaia - Superficie deprimida com formato alongado situada entre a planície do Bananal, a leste, e as Chapadas dos Guimarães e dos Parecis, a oeste. Consiste de uma superficie com altitudes entre 200 e 300 metros, basicamente esculpida e modelada em rochas cristalinas da Plataforma Sul Amazônica e metassedimentares do cinturão Paraguai-Araguaia. $O$ relevo apresenta-se dissecado com formas convexas no topo, destacando-se um setor entre os rios Araguaia e das Mortes que é constituido de relevos residuais esculpidas em rochas do Grupo Cuiabá.

37 - Planície do Bananal - Extensa faixa rebaixada embutida na depressão do Araguaia e que acompanha o rio Araguaia e das Mortes, cujas altitudes situam-se entre as cotas de 200 e 220 metros. É constituída de depósitos quaternários consolidados da formação Pantanal e de sedimentos inconsolidados holocênicos. Podem ser distinguidos dois tipos de feições características na área: planícies fluviais com presença de lagoas, lagos de meandros e bancos de areias e praias, e a outra, denominada área de acumulação inundável, constituída dos terrenos baixos e sujeita ao preenchimento periódico por águas pluviais.

\section{Considerações Finais}

Entendendo que o trabalho até aqui desenvolvido mostra resultados satisfatórios, queremos assinalar que os conceitos de morfoestrutura que acompanham toda metodologia de cartografia geomorfológica desenvolvida por Ross são de pleno conhecimento dos autores. Por esta razão, queremos salientar que as unidades morfoesculturais definidas neste trabalho, 
encontram-se esculpidas no Cinturão Orogênico Paraguai-Araguaia, Plataforma Amazônica e nas bacias sedimentares do Paraná (Paleozóica), Parecis (Mesozóica), bem como nas do Pantanal, Guaporé e Bananal (Cenozóicas).

Considerando porém, a limitação de espaço disponível para adentrar na questão das morfoestruturas, somado aos objetivos mais imediatos deste trabalho, qual seja, servir de referência aos alunos de primeiro e segundo graus, bem como, aos estudantes dos cursos de Geografia de Mato Grosso, julgamos oportuno, neste momento, definir, delimitar e apresentar somente as unidades morfoesculturais.

Em trabalho futuro, após ser analisado e debatido de forma adequada por outros profissionais que trabalham com o tema, serão ampliadas e aprofundadas as discussões, bem como, descritos detalhadamente os limites, o embasamento geológico, as formas de relevo, a hidrografia, bem como outras questões geomorfológicas.

\section{Referências Bibliográficas}

AB'SABER A. N. - Provincias Geológicas e Domínios Morfoclimáticos no Brasil, in Geomorfologia 20, IGEOG/USP, São Paulo, 1969

AZEVEDO, A. - O Planalto Brasileiro e o Problema da Classificação de suas formas de relevo. Boletim Paulista de Geografia, São Paulo, (2): 43-53, 1949.

BASENINA, N.V.; ARISTARCHOVA, L.B. LUKASOV, A.A. - "Methos of Morphostrutural Analysis", - Geomorphological Mapping-Comission on Geomorphological Survey and Mapping of UGI, Praga, 1972.

BRASIL, A. \& ALVARENGA, S.M. - Relevo. In: Geografia do Brasil, Volume 1, Região CentroOeste, IBGE, R.J., 1988, p. 53-72.

FRANCO, M.S.M. \& PINHEIRO, R. - Geomorfologia da Folha SE. 21 - Corumbá e parte da Folha SE. 20, Série Levantamento dos Recursos Naturais, M.M.E., Projeto Radambrasil, vol. 27, Rio de Janeiro, 1982.

GERASIMOV, I. P. \& MECERJAKOV, J.A. Morphoestructure. In: FAIRBRIDGE, R. W. (ed)."The Encyclopedia of Geomorphology"Reinhold Book - New York - 1968.

KUX, J., H., BRASI, A. E. e FRANCO, M. do S. M. Geomorfologia. Folha SD.20 Guaporé, Série Levantamento de Recursos Naturais, M.M.E., Projeto Radambrasil, vol. 19, Rio de Janeiro, 1979.
MAMEDE, L.; ROSS, J.L.S., SANTOS, L.M., NASCIMENTO, M.A.L.S. - Geomorfologia. da Folha SE.22 - Goiânia, Levantamento de Recursos Naturais, M.M.E., Projeto Radambrasil Vol. 31, Rio de Janeiro, 1983.

MAMEDE, L., NASCIMENTO, M. A. L. S. do e FRANCO, M.S.M. Geomorfologia, da Folha SD. 22

- Goiás, Levantamento de Recursos Naturais, M.M.E., Projeto Radambrasil Vol. 25 Rio de Janeiro, 1981.

MAMEDE, L.; ROSS, J.L.S. e SANTOS, S.L.M. dos. geomorfologia da folha SC.22 - Tocantins, Levantamento de Recursos Naturais, M.M.E., Projeto Radambrasil Vol. 22, Rio de Janeiro, 1981.

MECERJAKOV, J.P. - "Les Concepts de Morphostruture et de Morphosculture: Un Novel Instrument de I'analyse Geomorphologique.", In Annales de Geographie, 77 e anées 423. Paris, 1968.

MELLO, D.P. \& FRANCO, M.S.M. Geomorfologia da Folha SC. 21 - Juruena, Série Levantamentos de Recursos Naturais, M.M.E, Projeto Radambrasil, vol. 20, Rio de Janeiro, 1980 .

MELO, D.P., COSTA, R.C.R, NATALI FLHO, T. Geomorfologia da Folha SC 20 - Porto Velho, Série Levantamentos dos Recursos Naturais, M.M.E., Projeto Radambrasil, vol. 16, Rio de Janeiro, 1978.

ROSS, J.L.S. - Registro Cartográfico do Fatos Geomorfológicos e a Questão da Taxonomia do Relevo. In: Revista do Depto. de Geografia, n. 06, FFLCH/USP, São Paulo, 1992.

ROSS, J.L.S. - Relevo Brasileiro, uma nova proposta de classificação. In: Revista do Depto. de Geografia, n 04, FFLCH/USP, São Paulo, 1985.

ROSS, J. L. S. \& MOROZ, I.C., - Mapa Geomorfológico do Estado de São Paulo. In: Revista do Depto. de Geografia, n. 10, FFLCH/USP, São Paulo, 1996.

ROSS, J.L.S. \& SANTOS, L.M. - "Geomorfologia da Folha SD 21 - Cuiabá, Série Levantamento dos Recursos Naturais, N.M.E. - Projeto Radambrasil, vol. 26, Rio de Janeiro, 1982.

VENTURA, L.M.; D'AVILA, L.M; BARBOSA, G.V. "Geomorfologia da Folha SB 21 - Tapajós, Série Levantamento dos Recursos Naturais, D.N.P.M. Projeto Radam, vol. 07, Rio de Janeiro, 1975.

WERLE, H.S.; BORGES, C.A; ROSA, D.B.; MORAES, E.P.; SILVA, L.B.S.M.; PAIVA D.J.Geomorfologia. In: Plano de Conservação da Bacia do Alto Paraguai. UFMT/FEMA-MT/EMBRAPACPAP/PNMA. 


\section{UNIDADES DE RELEVO DEFINIDAS PARA O ESTADO DE MATO GROSSO}

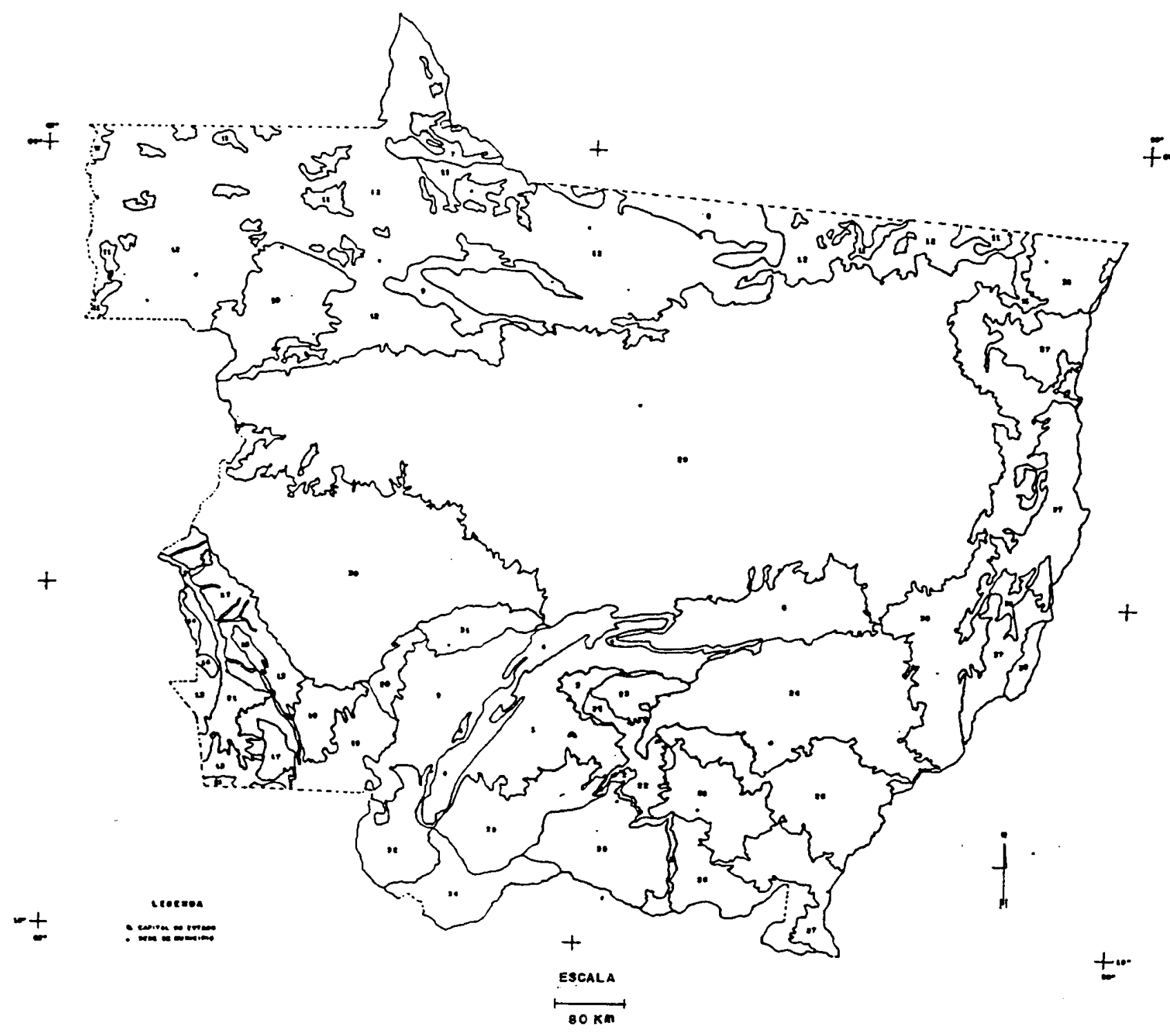

UNIDADES DE RELEVO

LOCALLZAÇÃO DO ESTADO

1 - Depressjo Cuiabona

2 - Depressto de Sto Jeronima-Mirnoso

3 - Planalto do Anuda-Mutum

4. - Serras residuais do Alto Paraguai

5 - Depressto do Alto Paraguai

6. Depressto interplanálica de Paranatinga

7. Serra dos Apiacts

8- Setor Monidional das Serras o Chapada do Cachimbo

9. Serra dos Caiabis

10 - Chapada de Dardaneloa

11- Planatos Residuais do

19 - Planatios Residuais do Norte de Mato Grosso

12 - Depressio Sul Amazónic

13. Depressiso do Guaport

14- Sern de Ricardo Franco

15 - Serre de Sto Vicente

Sanjo do de Cristas das serras da Borda, do Cágado.

17 - Santo do Aguapet e do Caldeirto

18 - Planato Santa Bárbera

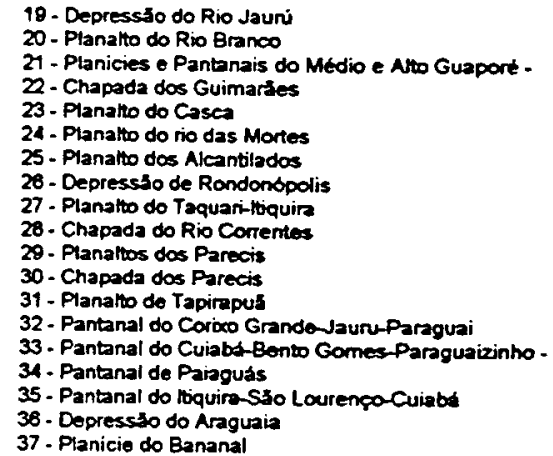

- Depressajo do Rio Jauni

21 - Planicies e Pantanais do Medio e Nto Guaporte

22. Chapada dos Guimarses

dos Parecis

- Chapada dos Parecis

列

35 - Pantanal do liquire-S5o Lourenga-Cuiab

38. Depressto do Araguaia

\section{$+$}

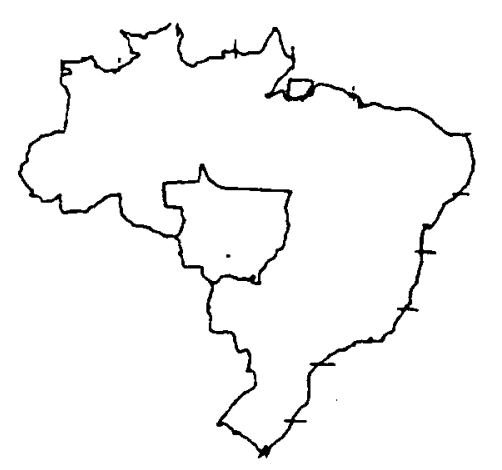

